\title{
Mapping Iranian patents based on International Patent Classification (IPC), from 1976 to 2011
}

\author{
Alireza Noruzi \\ Mohammadhiwa Abdekhoda*
}

\begin{abstract}
Patents are used as an indicator to assess the growth of science and technology in a given country or area. They are being examined to determine research potentials of research centers, universities, and inventors. The aim of this study is to map the past and current trends in patenting activities with a view to better understanding and tracking the changing nature of science and technology in Iran. The patenting activity in the Iran was investigated for the period 1976-2011, based on the USPTO, WIPO, and EPO (Esp@cenet). We analyzed the affiliation of inventers and collected patents which have at least an Iranian inventor. The collected data were analyzed applying Microsoft Excel. Analytical results demonstrate that between 1976 and 2011, 212 patents have been registered by Iranian inventors in the three above-mentioned databases. The average number of Iranian patents registered per year has increased significantly from 25 in 1976-1980 period to 119 in 2006-2011. It was noted that the highest number of registered patents $(27 \%)$ were in 'chemistry, metallurgy"' area of International Patent Classification (IPC), followed by "human necessities", (18\%), "electricity" (17\%), and "performing operations; transporting", $(15 \%)$. Overall, it can be concluded that patent-activities are highly countryspecific, the results indicate that Iran is focused on "chemistry, metallurgy" technology.
\end{abstract}

Keywords: Patents, International patent offices, Patent database, Iranian inventors, Scientometrics, Patent trends, Patent analysis, Content analysis, Topic map analysis, Iran.

\footnotetext{
${ }^{*}$ A. Noruzi

Faculty of Library and Information Science, University of Tehran, Tehran, Iran. E-mail: noruzi@ut.ac.ir

M. Abdekhoda

Department of Health Information Management, School of Health Management and Information Sciences, Tehran University of Medical Sciences, Tehran, Iran. E-mail: abdekhoda@razi.tums.ac.ir
} 


\section{Introduction}

A patent is a property right granted by a government to an inventor or applicant of a new invention, giving the inventor the right to make or sell the new invention for a limited amount of time, by excluding others from making, using, and selling the invention.

A patent is a scientific technical description of an invention, which is not disclosed elsewhere later (Bregonje 2005). The patent is intended to serve four functions: (1) to protect inventors from imitations; (2) to stimulate inventive activity; (3) to encourage investment in the products of inventive activity; and (4) to disseminate technical information to the public as a means to facilitate invention activities and innovation for the benefit of the society (Abbott 2007).

Patents are a key indicator of innovation, measuring technology development, innovative activities and innovative performance in terms of new technologies, new products, and new processes. Patent intelligence is an excellent tool to understand the development of a country's knowledge-based economy. Although patent indicators come with serious limitations, they remain a unique resource for analysis of the progress of technology innovation.

The number of patents acquired by a country reveals the technology innovation performance of that country. Patents are also a key indicator of technological competitiveness of a country or a company (Wu and Liu 2006). Patents, as primary sources of information, are important to research and scientific development and are unique information sources for technical information. Patent data enable researchers and innovators to:

- determine the novelty, patentability or validity of an invention

- monitor and forecast technological advances and trends

- conduct comprehensive research and evaluation

- develop more inventions; receives more research funding

- evaluate the research performance of institutions, departments or individuals

- track and compare competitors or colleagues and their progress and activities

- identify scientists and inventors for competitive intelligence and patent intelligence

- identify and address potential gaps in the marketplace and possible innovation opportunities

- find creative solutions to technological problems

- survey state of the art technology and identify good practice in the area

- determine the extent of coverage of patent protection

- prevent and avoid duplication of innovation, and, consequently, a waste of resources

- avoid or reduce patent infringement claims

Patents attached to a product, the utility of a product, a (production) process, an industrial design, or for a particular discovery not only act as an indicator of reliability for the product or process, 
but also demonstrate the technological capabilities and productivity of the company. Thus analyzing patents of a country or company can reveal their technological capability, technology leadership and partnerships, proprietary knowledge and technology, competitiveness, and possibilities of innovating and creating novel patented products, etc. (Bhattacharya 2007).

Patents have long been known as a useful source of information, especially in relation to subject trends and other analyses (List 2010). Patents mapping can give a general picture of a country's focused technologies, and are also in line with the country's economic development. More importantly, since the most valuable asset of a patent lies in its applicability, all invention patents must be useful, producible, and suitable for the industry. As a result, patent classification analysis not only provides a better understanding of the current patent trends of a country, but also helps to evaluate the potential of a specific or rising industry (Chen et al. 2005).

This research analyzes patent classification to explore the Iranian patent-activity and industrial development, examining Iran's patent areas in a long-term perspective over the past 35 years. Patents are classified according to the International Patent Classification (IPC) schema. The IPC divides patentable technology into eight major sections:
A: Human necessities
B: Performing operations; Transporting
C: Chemistry; Metallurgy
D: Textiles; Paper
E: Fixed constructions
F: Mechanical engineering; Lighting; Heating; Weapons; Blasting
G: Physics
H: Electricity

Each patent is assigned classification code (class/sub-class/groups/sub-groups) based on the IPC. The classification code attached to a patent defines the technological class of the patent (Bhattacharya 2007). The IPC is a hierarchical patent classification system, serving as "a basis for the preparation of industrial property statistics which in turn permit the assessment of technological development in various areas"' (WIPO 2011).

Patent data has been used by an increasing number of researchers and institutions throughout the world to measure technological change and technological competences, and also to analyze specific operations for potential improvement, such as Comanor and Scherer (1969); Schmookler (1962, 1966, 1972); Basberg (1984); Pavitt and Patel (1988); Griliches (1990); Archibugi (1992); Archibugi and Pianta (1992); Braun et al. (1995); the OECD (1994); Grupp et al. (2003); the European Commission (1997, 2003); Meyer (2002); Ramani and Looze (2002a, 2002b); Kung and Lin (2003); Ganguli (2004); Van Zeebroeck et al. (2005); Guan and He (2007); Leydesdorff and Meyer (2010). 


\section{Purpose and objectives}

Mapping the patent-activity of a country based on IPC is the easiest way to measure the technological specialization and technological scope of the country through the distribution of its patents over various technological areas.

The purpose of this study is to map Iranian patents registered in the USPTO, WIPO, and EPO (Esp@cenet) during 1976-2011, based on the IPC. In other words, this study analyzes subject trends of the Iranian patents based on IPC.

Our analysis uses these data to address our research question: what subject areas of knowledge are involved? We are interested to know in what subject areas Iranian inventors demonstrate innovative technical competencies. It is also important to evaluate a country's patent activities and identifying subject trends, or comparing the development of major patent fields.

In the above context, the two main questions addressed are:

1. What are the most patent-productive fields in Iran?

2. What are the country-specific characteristics of the patent-activity?

Thus, the purpose of the study is to identify and describe national patterns in the patent activity, so that new prospects for future theoretical and empirical research may be opened.

\section{Materials and methods}

Analysis of patent data has been studied by many researchers to be an important approach in assessing various aspects of $\mathrm{R}$ and $\mathrm{D}$. The methodological goals of this research are to examine patent trends and patterns in patent applications in specific areas. The methodology applies the patent map analysis onto Iranian patents issued between January 1, 1976 and September 30, 2011.

This research uses the IPC analysis to study the Iranian patent-activity over the last 35 years. The IPC is the primary patent classification system in the world. Thus, the IPC is the main system for categorization of patent trends in this study of Iranian patent applications. Each IPC has its corresponding technology classification. The IPC classification analysis helps the analyzer to evaluate the technology classification distribution of patents, assessing the overall technology trend of a country over time.

The patenting activity in Iran was investigated for the period 1976-2011, using the patent databases of the USPTO, WIPO, and EPO (Esp@ @enet). We analyzed the affiliation of inventers and collected patents which have at least one Iranian inventor. 
Patents possess two fields that contain bibliographic information relevant to the calculation of where the patent originates: the inventor field (inventor address) and the applicant (assignee) field. An inventor is necessarily a natural (physical) person, whereas an applicant (assignee) can be a natural person and/or an institution. These fields are used to compute statistics on two different indicators, namely, invention and intellectual property (IP). The location of inventors provides a proxy for the creativity of countries, whereas the location of ownership of IP, particularly of institutional IP, provides an indicator of the potential economic impact of inventions (Parent et al. 2003).

A good patent searching strategy is a prerequisite to patent analysis and technology trends. By using appropriate search strategy, the patent data were manually retrieved, collected from the above-mentioned databases by searching the country name (Iran), country code (IR), and the name of capital cities (e.g., Tehran, Tabriz, Shiraz, ...). The resulting data were analyzed using tables and percentages. For each patent, we extracted the key information, including the IPC classification of the invention, as well as the province or city of the inventor residence.

\section{Search strategies on the USPTO}

In order to identify the Iranian patents, we used two different search strategies on the " advanced search" of the USPTO database:

1. Search by "inventor country (ICN)" as follows (ICN/IR), where IR is the country code for Iran. In this situation, many irrelevant patents were retrieved.

2. Search by "inventor city (IC)', for example, IC/Tehran, IC/Isfahan, IC/Shiraz, etc. The "inventor city", capital cities, was used as a complement strategy in order to complete the data set.

\section{Search strategies on the EPO}

Patent search was conducted on worldwide Espacenet. Each patent was assigned to a country according to the institute to which each inventor was affiliated. To do this, the advanced search form of Espacenet was used. On this form, the "applicant(s)" field was used to find Iranian patents. Note that the country name and the name of the capital cities were searched. For example:

Applicant = Iran

Applicant $=$ Tehran

Applicant $=$ Isfahan 


\section{Search strategies on the WIPO}

On the "structured search" option of the WIPO PATENTSCOPE, "applicant address (AAD)" and "inventor address (IAD)" were used. The country name and the name of the capital cities were searched. For example,

\section{AAD/TEHRAN}

\section{IAD/TEHRAN}

Finally, all data of Iranian patents have been cumulated and analyzed to measure and map Iranian patent-activity. Repeated data were removed. For example, when a patent was registered in three above-mentioned databases, only one of them counted. The result set contains 222 patents, which have at least an Iranian inventor. We distinguish patents by reference to their IPC. In each data set, we count the number of patents of Iran by technological class for the covered period, according to the main IPC class of the patent.

In this subject analysis, patent data is assembled for the period (1976 to September 2011) to reveal patterns in Iranian patenting. We are especially interested in the distribution of Iranian patents according to IPC-class designation. In method, this analysis falls within the growing tradition of patent-count analysis. While we attempted to conduct a comprehensive search of the Iranian patents, it is possible that we missed some cases.

\section{Results}

Patents are classified according to the IPC schema. This section describes the distribution of Iranian patent-activity by subject class. Tables 1, 2, 3 and 4 present patent content maps from 1976 to 2011.

\section{USPTO patent trends}

Table 1 exhibits the amounts of Iranian patents granted by the USPTO during 1976-2011 in each IPC subject area. Table 1 indicates that most of the patents are in the subject areas of “chemistry, metallurgy" (23\%), followed by electricity (19\%), and physics (16\%). Since all the percentages in Table 1 and the following tables have been rounded to integers, the sum of the percentages in some tables may be greater or less than 100 by $1-2 \%$. 
Table 1. Iranian patents registered in the USPTO in each IPC subject area

\begin{tabular}{|c|l|c|c|c|}
\hline No. & \multicolumn{1}{|c|}{ Subject } & $\begin{array}{c}\text { IPC } \\
\text { subject }\end{array}$ & Freq. & Per. \\
\hline 1 & Human Necessities & $\mathrm{A}$ & 14 & 11.96 \\
\hline 2 & Performing Operations; Transporting & $\mathrm{B}$ & 15 & 12.82 \\
\hline 3 & Chemistry; Metallurgy & $\mathrm{C}$ & 27 & 23.07 \\
\hline 4 & Textiles; Paper & $\mathrm{D}$ & 3 & 2.56 \\
\hline 5 & Fixed Constructions & $\mathrm{E}$ & 7 & 5.98 \\
\hline 6 & Mechanical Engineering; Lighting; Heating; Weapons; Blasting & $\mathrm{F}$ & 9 & 7.69 \\
\hline 7 & Physics & $\mathrm{G}$ & 19 & 16.23 \\
\hline 8 & Electricity & $\mathrm{H}$ & 23 & 19.65 \\
\hline \multicolumn{2}{|c|}{ Total } & 117 & 100 \\
\hline
\end{tabular}

\section{EPO patent trends}

Table 2 shows the number of Iranian patents collected from the EPO in each IPC subject area. Table 2 reveals that the majority of granted patents are in "chemistry; metallurgy" (34\%), followed by "human necessities" (23\%), and "performing operations; transporting" (23\%).

Table 2. Iranian patents registered in the EPO in each IPC subject area

\begin{tabular}{|c|l|c|c|c|}
\hline No. & \multicolumn{1}{|c|}{ Subject } & $\begin{array}{c}\text { IPC } \\
\text { subject }\end{array}$ & Freq. & Per. \\
\hline 1 & Human Necessities & $\mathrm{A}$ & 12 & 23.07 \\
\hline 2 & Performing Operations; Transporting & $\mathrm{B}$ & 12 & 23.07 \\
\hline 3 & Chemistry; Metallurgy & $\mathrm{C}$ & 18 & 34.61 \\
\hline 4 & Textiles; Paper & $\mathrm{D}$ & 1 & 1.92 \\
\hline 5 & Fixed Constructions & $\mathrm{E}$ & 0 & 0 \\
\hline 6 & Mechanical Engineering; Lighting; Heating; Weapons; Blasting & $\mathrm{F}$ & 1 & 1.92 \\
\hline 7 & Physics & $\mathrm{G}$ & 2 & 3.84 \\
\hline 8 & Electricity & $\mathrm{H}$ & 6 & 11.53 \\
\hline \multicolumn{2}{|c|}{ Total } & & 52 & 100 \\
\hline
\end{tabular}

\section{WIPO Patent Trends}

Table 3 presents the number of Iranian patents registered in the WIPO in each IPC subject area. Table 3 illustrates that the largest number of Iranian patents were awarded in the "human necessities" (33\%), followed by “chemistry; metallurgy” (27\%), and "electricity” (12\%). 
Table 3. Iranian patents registered in the WIPO in each IPC subject area

\begin{tabular}{|c|l|c|c|c|}
\hline No. & \multicolumn{1}{|c|}{ Subject } & $\begin{array}{c}\text { IPC } \\
\text { subject }\end{array}$ & Freq. & Per. \\
\hline 1 & Human Necessities & A & 16 & 33.33 \\
\hline 2 & Performing Operations; Transporting & B & 5 & 10.41 \\
\hline 3 & Chemistry; Metallurgy & C & 13 & 27.08 \\
\hline 4 & Textiles; Paper & D & 0 & 0 \\
\hline 5 & Fixed Constructions & E & 2 & 4.16 \\
\hline 6 & Mechanical Engineering; Lighting; Heating; Weapons; Blasting & F & 1 & 2.08 \\
\hline 7 & Physics & G & 5 & 10.41 \\
\hline 8 & Electricity & H & 6 & 12.5 \\
\hline \multicolumn{2}{r|}{ Total } & 48 & 100 \\
\hline
\end{tabular}

A comparison between the data presented in the three tables above show that while the largest number of patents were found in the area of "chemistry; metallurgy", there are significant differences in the distribution of the remaining patents in the different databases. These differences may be either due to the patent office's decision to issue the patent, or due to the inventor's or applicant's choice and financial position.

\section{Cumulative data of patent analysis}

Figure 1 represents the distribution of Iranian patents for the years 1976-2011. Figure 1 displays the numbers of Iranian patents. It can be seen that the number of patents has increased. Furthermore, the data show that the first patent granted to Iran is dated 1976.

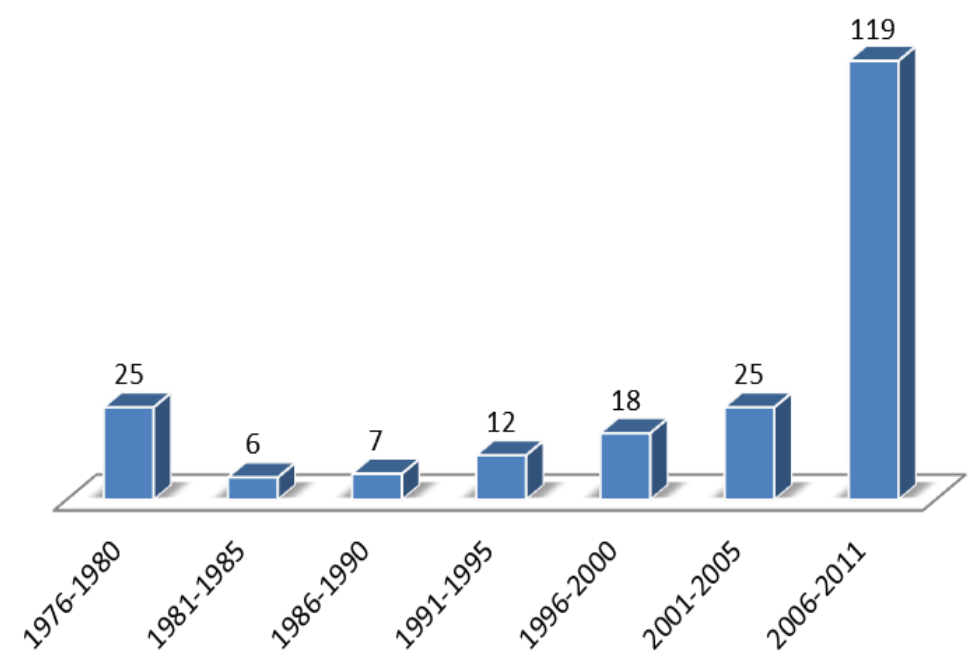

Figure 1. Distribution of Iranian patents by year 
Figure 1 demonstrates that between 1976 and 2011, 212 patents have been registered by Iranian inventors in the three above-mentioned databases. The average number of Iranian patents registered per year has increased significantly from 25 in 1976-1980 period to 119 in 20062011. In mapping the absolute dimensions of the Iranian patent-activity, we see an averaged patent-grant rate of about 6 patents per year over the 35 years period in question.

If the data is divided into two periods 1976-1995 and 1996-September 2011, a marked-but not necessarily significant - gain is seen, from 2.63 to 10.8 per year. However, it should be noted that these rates are not necessarily meaningful, as they could reveal more about the economic conditions of the country, the processing time of patent applications, and so forth.

Figure 1 also shows that there is a strong increase in patenting from 2001 to 2011. This increase is due to the major national investment in $\mathrm{R}$ and $\mathrm{D}$. The financial encouragement for scientific publications and patents is one of the key strategies being supported by the Iranian government especially since 2000. The government also draws attention to international rankings for science and technology.

Our main results are summarized in Table 4. This table shows the cumulative data of all Iranian patents registered in the USPTO, WIPO, and EPO, removing repeated data. The table below contains the subject areas based on the IPC-classes for the period as a whole. An initial look at the size and subject distribution of patents granted in the USPTO, WIPO, and EPO to Iranians for the period reveals a relatively small and concentrated set of patenting activity.

Table 4 and Figure 2 indicate that the largest number of registered patents $(27 \%)$ were concentrated in "chemistry, metallurgy" area of the IPC, followed by "human necessities" (18 $\%)$, "electricity" (17\%), and "performing operations; transporting", (15\%). It is worth noting that the top-4 class activities claim fully $77 \%$ of the total patent-activity.

Table 4. Total number of Iranian patents in three databases

\begin{tabular}{|c|l|c|c|c|}
\hline NO. & \multicolumn{1}{|c|}{ Subject } & $\begin{array}{c}\text { IPC } \\
\text { subject }\end{array}$ & Freq. & Per. \\
\hline 1 & Human Necessities & A & 42 & 19 \\
\hline 2 & Performing Operations; Transporting & B & 32 & 14 \\
\hline 3 & Chemistry; Metallurgy & $\mathrm{C}$ & 60 & 27 \\
\hline 4 & Textiles; Paper & $\mathrm{D}$ & 4 & 2 \\
\hline 5 & Fixed Constructions & $\mathrm{E}$ & 9 & 4 \\
\hline 6 & Mechanical Engineering; Lighting; Heating; Weapons; Blasting & $\mathrm{F}$ & 11 & 5 \\
\hline 7 & Physics & $\mathrm{G}$ & 27 & 12 \\
\hline 8 & Electricity & $\mathrm{H}$ & 37 & 17 \\
\hline & & & $\mathbf{2 2 2}$ & 100 \\
\hline
\end{tabular}




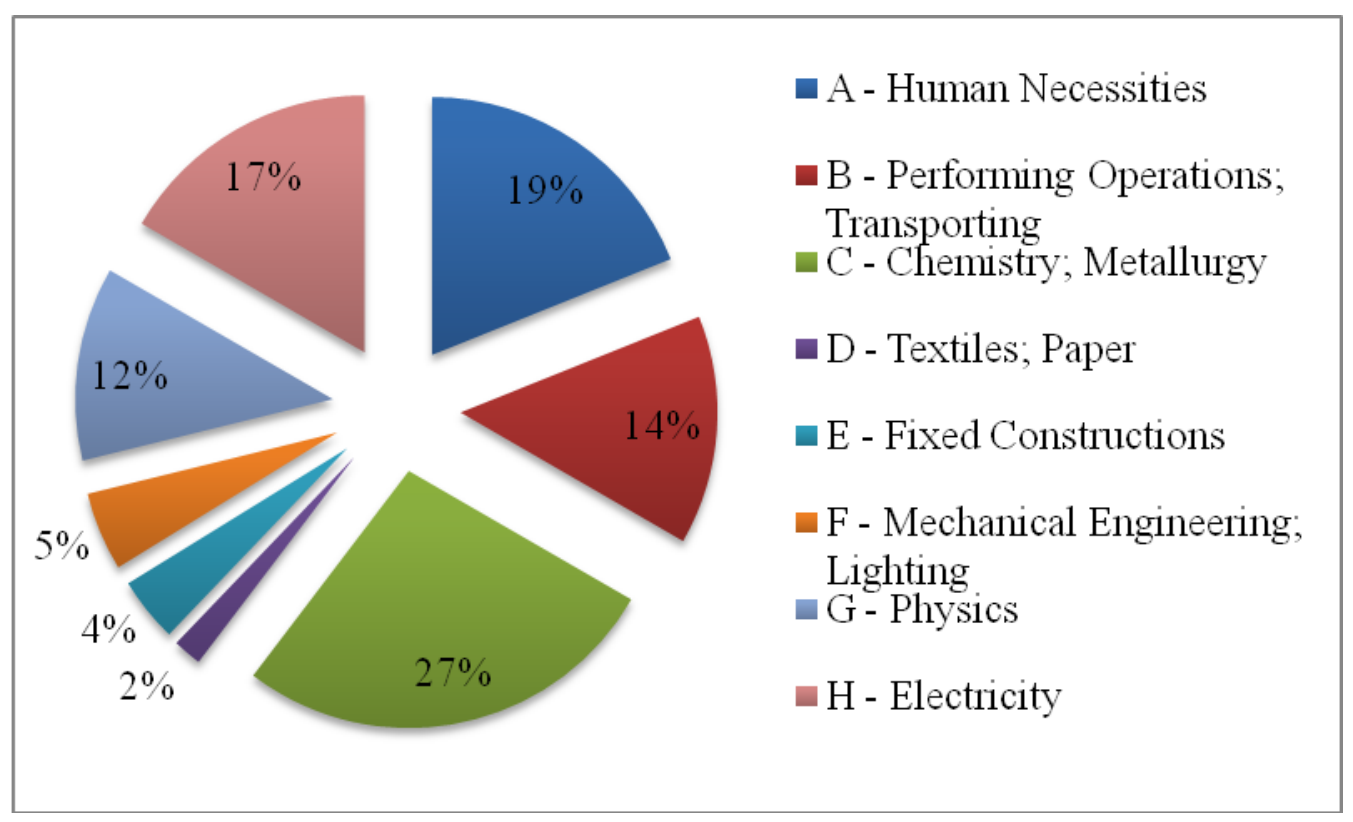

Figure 2. Patent amounts in each class of the IPC

It is interesting that in the case of China, Guan and He's survey showed that electricity (sector H) is the most productive sector with 1,032 patents, accounting for $26.4 \%$ of the total. Followed by physics (sector G), human necessities (sector A) and chemistry (sector C), with shares of 17.4, 16.8 and $16.0 \%$, respectively (Guan and He 2007).

\section{Discussion and conclusion}

Patent statistics can be used to analyze the relative competitiveness of a country at the international level. The current study used IPC for identifying the industrial sectors that the Iranian patents addressed. This analysis on subject distribution of Iranian patents helps us to map the Iranian patent-activity over the past 35 years. In our survey of mapping Iranian patents based on the IPC, four significant and dominant classes of Iranian patents are: "chemistry, metallurgy", "human necessities", "electricity", and "performing operations; transporting". The patent filing statistics of Iran reveal that the number of patents is low, but overall this study reflects that the number of Iranian patents shows continued growth with a high emphasis on "chemistry, metallurgy". It is noticeable that the field of chemistry, in Iran, has also the highest number of papers published in the international journals. This case study aims to contribute to a better understanding of patent trends by means of quantitative analysis on Iranian patents granted by the USPTO, WIPO, and EPO during 1976-2011. However, the main limitation of this study is that only Iranian patents granted by international patent offices were examined, and patents registered by the national patent office were not included in the study. 


\section{Acknowledgments}

The authors would like to thank the anonymous reviewers for their valuable comments that helped to improve the paper.

\section{References}

Abbott, F. M. (2007). Intellectual property rights in world trade. In A. T. Guzman \& A. O. Sykes (Eds.), Research handbook in international economic law (pp. 444-484). Northampton: Edward Elgar Publishing.

Archibugi, D. (1992). Patenting as an indicator of technological innovation: a review. Science and Public Policy, 19(6), 357-368.

Archibugi, D., \& Pianta, M. (1992). The technological specialization of advanced countries. Report to the EEC on international science and technology activities. Boston: Kluwer.

Basberg, B. L. (1984). Patent statistics and the measurement of technological change: an assessment of the Norwegian patent data, 1840-1980. World Patent Information, 6(4), 158164.

Bhattacharya, S. (2007). Delineating the patent data: a case study of prolific patenting institutions of India and China. DESIDOC Bulletin of Information Technology, 27(1), 87-95.

Braun, T., Glanzel, W., \& Grupp, H. (1995). The scientometric weight of 50 nations in 27 science areas, 1989-1993. Part I. All fields combined, mathematics, engineering, chemistry and physics. Scientometrics, 33(3), 263-293; Part II. Life Sciences, Scientometrics, 34(2), 207237.

Bregonje, M. (2005). Patents: a unique source for scientific technical information in chemistry related industry? World Patent Information, 27(4), 309-315.

Chen, D.-Z., Chang, H.-W., Huang, M.-H., \& Fu, F.-C. (2005). Core technologies and key industries in Taiwan from 1978 to 2002: a perspective from patent analysis. Scientometrics, 64(1), 31-53.

Comanor, W. S., \& Scherer, F. M. (1969). Patents statistics as a measure of technical change. Journal of Political Economy, 77(4), 392-398.

European Commission (1997). European report on science and technology indicators (REIST) 1997. Retrieved September $29, \quad 2011$ from http://cordis.europa.eu/indicators/publications.htm

European Commission (2003). Third European report on science and technology indicators 2003. Retrieved September 29, 2011 from http://cordis.europa.eu/indicators/publications.htm

Ganguli, P. (2004). Patents and patent information in 1979 and 2004: a perspective from India. World Patent Information, 26(1), 61-62.

Griliches, Z. (1990). Patent statistics as economic indicators: a survey. Journal of Economic Literature, 28(4), 1661-1707.

Grupp, H., Lacasa, I. D., \& Schmoch, U. (2003). Tracing technological change over long periods in Germany in chemicals using patent statistics. Scientometrics, 57(2), 175-195.

Guan, J., \& He, Y. (2007). Patent-bibliometric analysis on the Chinese science - technology linkages. Scientometrics, 72(3), 403-425.

Kung, M. H., \& Lin, H. Y. (2003). The dynamics of innovation in Taiwan: the patent analysis respective. In: S. C. H. Paul (Chair), International Conference on Industrial Science and Technology Innovation: Policy Issues and Challenges in a Critical Era, Taipei, Taiwan, 2003. 
Leydesdorff, L., \& Meyer, M. (2010). The decline of university patenting and the end of the Bayh-Dole effect. Scientometrics, 83(2), 355-362.

List, J. (2010). An A to X of patent citations for searching. World Patent Information, 32(4), 306312.

Meyer, M. (2002). Tracing knowledge flows in innovation systems. Scientometrics, 54(2), 193212.

OECD (1994). The measurement of scientific and technological activities using patent data as science and technology indicator - patent manual. Paris: OECD.

Parent, A., Bertrand, F., Côte, G., \& Archambault, E. (2003). Scientometric study on collaboration betweenIndia and Canada, 1990-2001: phase 1 of the 2004 Canada-India S and T mapping study. Prepared for: Departments of Foreign Affairs Canada, International Trade Canada, and Industry Canada. Science-Metrix 2003. Retrieved September 29, 2011 from http://www.science-metrix.com/pdf/Science-Metrix_CanadaIndia_Collaboration_Report.pdf

Pavitt, K., \& Patel, P. (1988). The international distribution of determinants of technological activities. Oxford Review of Economic Policy, 4(4), 35-55.

Ramani, S. V., \& De Looze, M.-A. (2002a). Country-specific characteristics of patent applications in France, Germany and the UK in the biotechnology sectors. Technology Analysis and Strategic Management, 14(4), 457-480.

Ramani, S. V., \& De Looze, M.-A. (2002b). Using patent statistics as knowledge base indicators in the biotechnology sectors: an application to France, Germany and the UK. Scientometrics, 54(3), 319-346.

Schmookler, J. (1962). Economic sources of inventive activity. The Journal of Economic History, 22(1), 1-20.

Schmookler, J. (1966). Invention and economic growth. Cambridge: Harvard University Press.

Schmookler, J. (1972). Patents, invention and economic change. Cambridge: Harvard University Press.

Van Zeebroeck, N., Van Pottelsberghe de la Potterie, B., \& Han, W. (2005). Issues in measuring the degree of technological specialisation with patent data. No. 05-016. RS, Working Papers CEB from ULB- Universite Libre de Bruxelles, April 2005. Retrieved September 29, 2011 from http://econpapers.repec.org/paper/solwpaper/05-016.htm

WIPO (2011). International Patent Classification (version 2011)-guide. Guide to the IPC (2011). $\quad$ Retrieved $\quad$ September $29, \quad 2011$ from http://www.wipo.int/export/sites/www/classifications/ipc/en/guide/guide_ipc.doc

Wu, Y.-C. J., \& Liu, H.-P. (2006). Technological innovation assessment of business-to-business electronic marketplaces. Journal of the American Society for Information Science and Technology, 57(8), 1093-1104.

\section{How to cite this paper}

Noruzi, Alireza, \& Abdekhoda, Mohammadhiwa (2012). Mapping Iranian patents based on International Patent Classification (IPC), from 1976 to 2011. Scientometrics, 93(3), 847-856. 